\title{
Design and Implementation of Intelligent Agricultural Product Logistics Vehicle Monitoring Terminal based on GPS/GPRS
}

\author{
DengMinghua $^{1, a}$, WangXiaozhi ${ }^{2, b}$ \\ ${ }^{1}$ School of Information Engineering, Wuhan Technology and Business University, Wuhan 430065, \\ China \\ ${ }^{2}$ School of Logistics Engineering, Wuhan University of Technology, Wuhan 430070, China \\ Xuexi123@163.com
}

Keywords: Intelligent logistics, Monitoring system, GPS/GPRS technology, RFID radio frequency, Embedded.

\begin{abstract}
According to the design requirement of the agricultural product intelligent logistics monitoring system, this paper uses integrate embedded technology to design a new intelligent logistics monitoring system based on GPS/GPRS. On this basis, this paper designs the GPS positioning module, RFID RF module and GPRS wireless network module by using ARM hardware system, and designs the external memory and memory expansion of the SD card, to complete the development of vehicle intelligent logistics monitoring system. Finally, this paper tests the RFID module, GPS module and GPRS wireless network module, the results show that the validation data is consistent with the write and re read result, the GPS module can achieve the positioning function, completing the communication with GPRS and the two functions of SMS and communication. For the GPRS network, its test results show that the GPRS network communication is normal, so as to verify the feasibility and reliability of the intelligent logistics monitoring system.
\end{abstract}

\section{Introduction}

With the development of economy and the improvement of people's living standards, people obtain food channels to become increasingly diverse. The circulation of goods frequently in the process of food transportation will inevitably lead to negligence, which will inevitably lead to food safety issues [1-3]. The security of agricultural products in China is in a special position in the national economy and the people's livelihood. Food safety has gradually become the main concern of people in daily life, how to quickly get the production data is a topic of consumer concern, so it is a problem to be solved how to establish a perfect product information system [4,5]. In the logistics transportation process, this paper uses the intelligent logistics monitoring system to carry on the whole tracking and identification for agricultural products circulation path and quality, so that the quality of agricultural products can be traced back, which provides a more valuable reference for the design of intelligent logistics monitoring system.

\section{The Function and Overall Framework of Agricultural Product Embedded Logistic Intelligent Monitoring System}

In the process of agricultural product transportation, the reasonable control of temperature and humidity can ensure the quality of agricultural products, so in the process of transportation, it is necessary to carry out real-time monitoring on the temperature and humidity [6-8]. The data acquisition device adopts intelligent terminal, the data is transmitted to the monitoring center by GPRS transmission network, and then the monitoring center can process information, finally through the internet and other information platform, they can provide data query and verification to provide traceability information for the agricultural sector, the design framework is shown in Figure 1. 


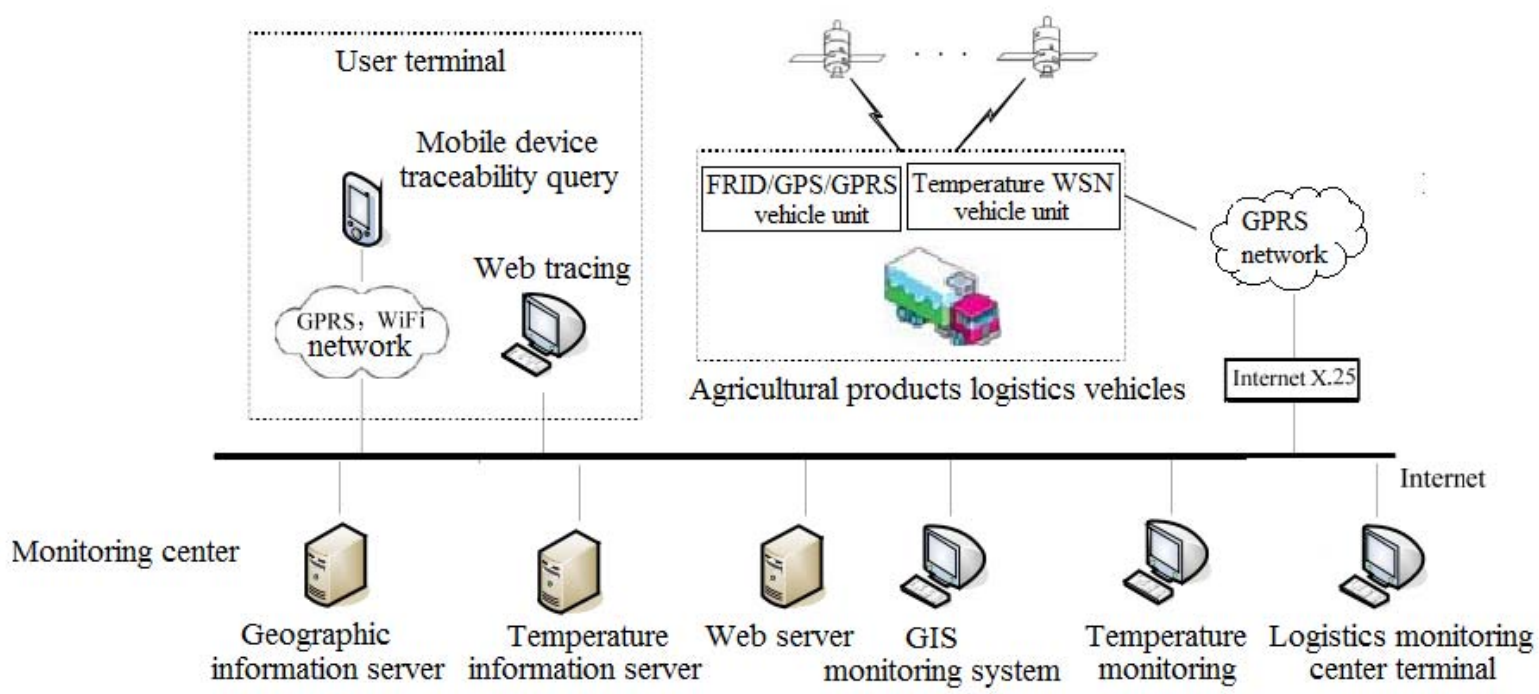

Fig. 1 The design framework of embedded intelligent logistic monitoring system

Figure 1 shows the design of the embedded agricultural products intelligent logistics monitoring system framework, which is generally divided into six parts, including the GPS, RFID agricultural product identification, GPRS wireless network, wireless sensor system, monitoring center and traceability query system. GPS system is mainly responsible for vehicle positioning, temperature and humidity control, wireless communication and the formation of wireless communication network, to achieve real-time data transmission and receive command; RFID is used for identifying agricultural products, providing vehicles and product verification, monitoring and distribution information; GPRS is mainly used for data communications, connecting vehicles and monitoring center; The wireless sensor network is a form of multi hop network, which provides the data for the logistics system; Monitoring center is responsible for determining the data and sending instructions for the temperature and humidity conditions, but also to provide historical data query and GIS functions, etc.; Traceability queries are mainly through the use of monitoring center data, to provide a complete traceability data information for the users and the relevant departments.

\section{Embedded Intelligent Module and GPRS Communication Design}

The hardware part of vehicle monitoring system designed by this paper includes GPS module, GPRS module, RFID module, SD module and FLASH module, and uses the modular embedded development approach, in which the connection between embedded motherboard and the module as well as the communication mode as shown in Table 1.

Table 1. Embedded board and module interface

\begin{tabular}{|c|c|l|}
\hline Function module & Communication mode & Connecting pin \\
\hline GPS module & USART1 & $\begin{array}{l}\text { PA1.USART3_TX-GPS_RX } \\
\text { PA2.USART3_RX-GPS_TX }\end{array}$ \\
\hline GPRS module & USART2 & $\begin{array}{l}\text { PA3.USART1_TX-GPS_RX } \\
\text { PA4.USART1_RX-GPS_TX }\end{array}$ \\
\hline RFID module & SPI & $\begin{array}{l}\text { PA5.SPI6_MOSI-TDIN } \\
\text { PA6.SPI6_MOSI-DOUT } \\
\text { PA7.SPI6_SCK-TCLK } \\
\text { PA8.SPI6_NNS-TCS }\end{array}$ \\
\hline FLASH module & SPI & $\begin{array}{l}\text { PB9.F_CS-CS } \\
\text { PB10.SPI_SCKF-CLK } \\
\text { PB11.SPI1_MISO-SO } \\
\text { PB12.SPI1_MISO-SI }\end{array}$ \\
\hline SD module & SDIO & $\begin{array}{l}\text { PB13.SDIO_D1-SD_DT1 } \\
\text { PB14. SDIO_D0-SD_DT0 }\end{array}$ \\
\hline
\end{tabular}


Table 1 shows the main interface distribution of embedded motherboard and module, the connection between interface and hardware devices can be component GSM network. The GSM network is the basis of GPRS technology by the use of network and hardware devices, and then it goes through the modification service software to achieve GPRS communication functions, in which the exchange process of communication business is shown in Figure 2.

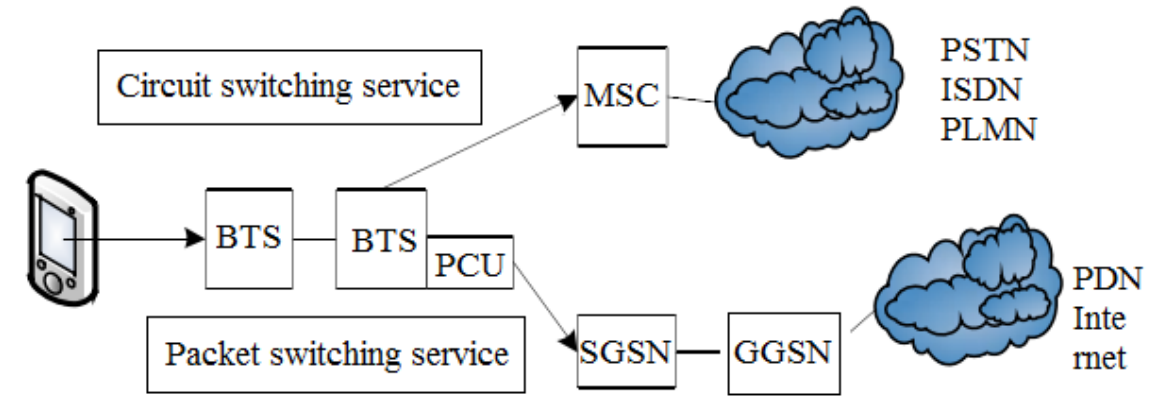

Fig. 2 GPRS business process

Figure 2 shows the process of GPRS business, GPRS business is mainly done by the GSM system. GSM system includes mobile station MS, base station subsystem BBS and network subsystem, in which the base station subsystem is mainly composed by the base station BTS and base station controller BSC; network subsystem includes mobile switching center MSC, operation maintenance center $\mathrm{OMC}$ and home location register, at the same time it also configures the authentication center AUC, device flag register EIR, etc..

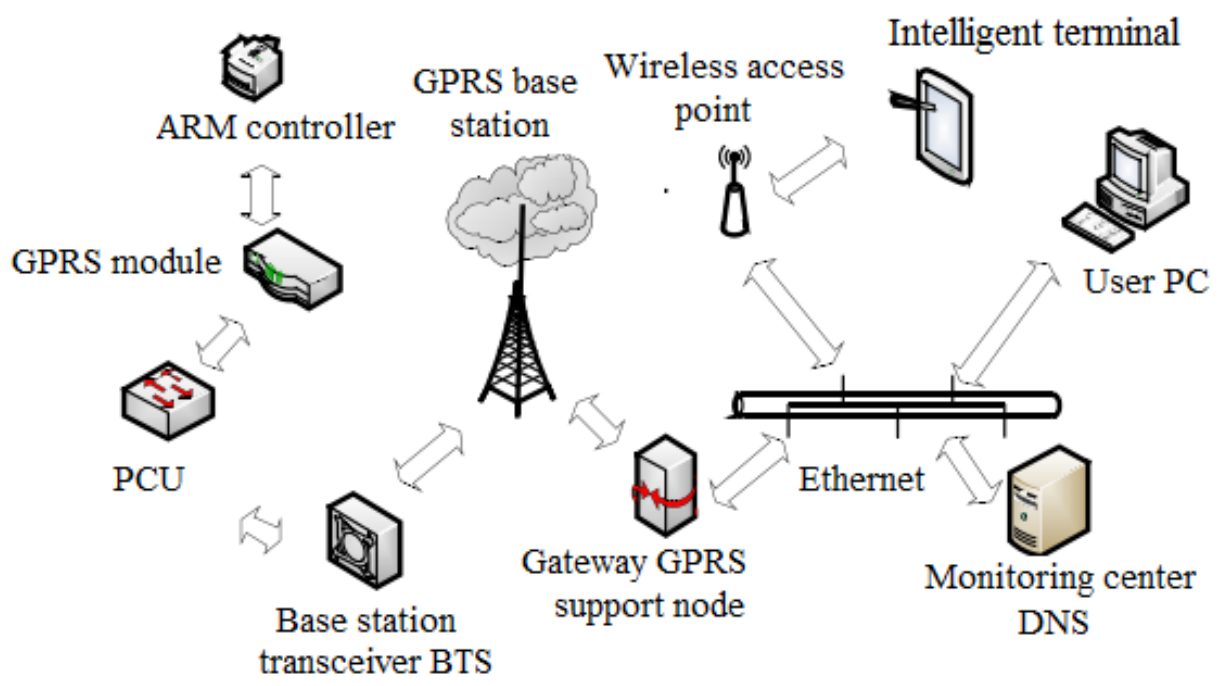

Fig. 3 GPRS implementation principle

Figure 3 shows the implementation principle of GPRS, this paper main uses the GPRS packet switching business, it goes through the ARM controller to control the GPRS module and build network, so as to achieve the vehicle monitoring terminal and GPRS network connection, finally to control data transceiver by sending GPRS commands.

\section{The Performance Test of Embedded Logistic Intelligent Monitoring System}

In order to verify the reliability of the system, the system has been tested. In this design, the FRID module of the vehicle monitoring system mainly includes two parts, one part is in the cab, and anther is in the transport container, the system can track and record the information of transportation and logistics [9-11]. The RFID physical is shown in Figure 4. 


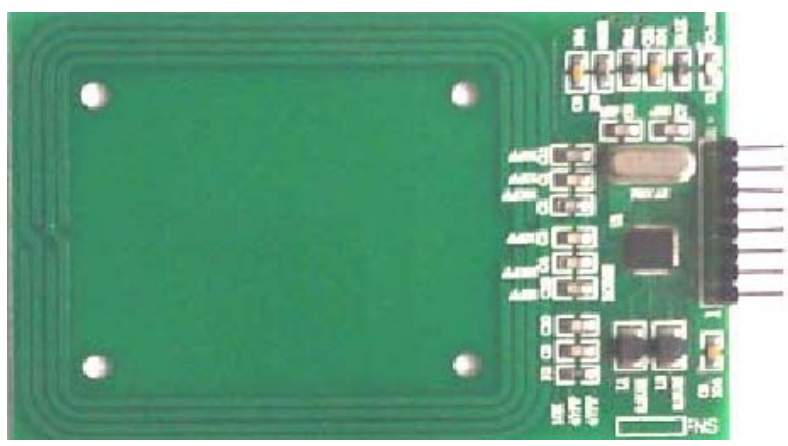

Fig. 4 RFID physical map

Figure 4 shows the physical map of RFID, RFID test mainly verifies the reader function, its main functions include data read, modify and password verification, through the simulation of serial data, the system can input operation instructions, to complete the IC card information read, and then to store data.

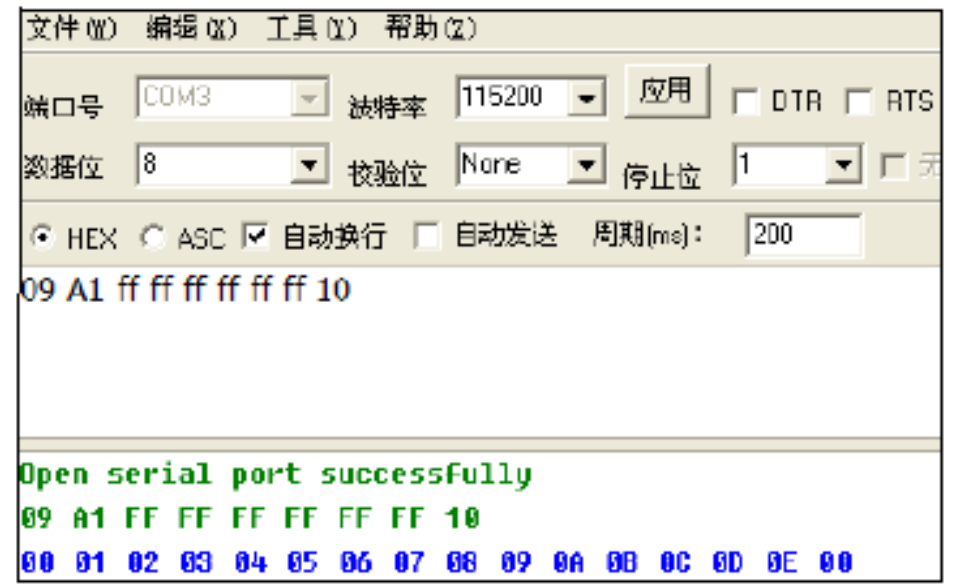

Fig. 5 RFID function test

Figure 5 shows the test results obtained by the test results of the RFID function. As shown in Figure 5, sending A0, A2, A1 and A3 commands, password verification, reading a data storage area are verified by the use of serial debugging assistant, and then by viewing the changes in the storage area to verify whether the normal function. Through the writing and re read results, Figure 5 can be seen that before and after the data validations are consistent, so as to verify the normal of the RFID function.

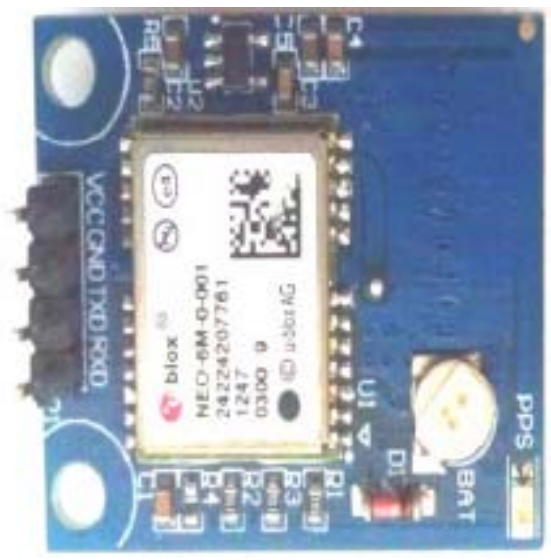

Fig. 6 GPS module physical map

Figure 6 shows the GPS physical map, the GPS map test mainly uses the drawing point method to send the specific information of geographic coordinates by the GPRS, and then the use of the periodic sampling method tests the positioning performance. The following results are obtained by testing [12-14]:

GPS TEST

SX1105116 
NMEA Data Upload:ON

Longitude:118.82407 E

Latitude:32.03756 N

Altitude: $9.9 \mathrm{~m}$

Speed:0.246km/h

Fix Mode:3D

Valid satellite:08

Visible satellite: 10

UTC Date:2015/08/08

UTC Time:06:06:42

From the test results, it can be seen that the GPS module can achieve the positioning function, completing the communication with GPRS and completing the two functions of SMS and communication.

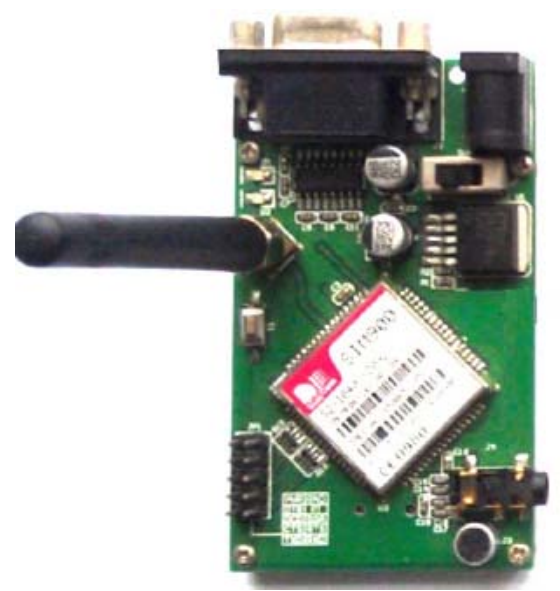

Fig. 7 GPRS module physical map

Figure 7 shows the GPRS physical map. In the process of GPRS network connection, it can get the current network module running state to successfully connect server after a certain time, and it can get IP address and whether the connection is successful and other tips, the following results are obtained by testing [15]:

SX1105116-GPRS

GPRS TCP Connection test

WK-UP: Exit test KEYO: Send data

IP address: 218.94.136.167 Port: 8086

State: Connection success

Send data: GPS-Data[MaxLen]

Receiving data: monitoring center has connected GPRS

Sending GPS-Data

From the test results, it can be seen that the GPRS module has successfully connected to the server, in which the IP address is 218.94.136.167. After the network connection is completed, the vehicle terminal receives the monitoring center GPRS message connected by a network port, and is sending GPS information to verify the feasibility of GPRS network.

\section{Summary}

Using GPS positioning technology, GPRS wireless communication, RFID module and embedded integration technology, this paper proposes a new vehicle intelligent logistic monitoring system based on GPS/GPRS and designs SD card's external memory and memory expansion, to complete the development of vehicle intelligent logistics monitoring system. At the same time, this paper has tested the intelligent logistics monitoring system, the test found that the RFID module can read, store and modify data effectively; the GPS module can realize the positioning function; the GPRS network can also complete the communication function effectively, so as to verify the reliability of the 
intelligent logistics monitoring system, which provides a valuable reference for the research of intelligent logistics monitoring system.

\section{Acknowledgement}

The work was supported by the Project of Hubei province Collaborative Innovation Center for Modern Logistics and Business with the project number 2011A201313 and the project name Research on the Embedded Intelligent Logistics Monitoring System

\section{References}

[1] Wang F., G. Cheng. The applications of WSN and RFID technology in product monitoring. Software, 2013, 8(32): 24-25.

[2] X.H. Ge. Analysis of cold chain logistics development status quo and its control factors in China. Commodity transportation and maintenance, 2014, 5(30): 31-33.

[3] C.X. Xiao, B.Y Zhu., Y.H. Chen. Design of intelligent vehicle systems. Journal of Nankai University, 2013, 44(6): 14-17.

[4] J.F. Zhang, Y. Zhu, G.S. Han. Vehicle monitoring system and data communication reliability research based on GPRS. Computer and modernization, 2014(12): 23-26.

[5] L.P. Xu, W.J. Shao. The design of vehicle wireless video server serial port expansion based on Cortex-M3. TV technology, 2012, 36 (1): 44-47.

[6] M.H. Deng, P.D. Luo, J.M. Zhong. The applications of TFT touch screen in the environment monitoring system based on Cortex-M3. Journal of applied electronic technology, 2014(13):198-206.

[7] J.L. Hu, Y. Lin. The supply shortage and its countermeasures of cold chain logistics in our country. Modern logistics, 2014(3):56-59.

[8] B. Guo, J.P. Qian, T.H. Zhang. Design of fruit and vegetable cold chain distribution environment information acquisition system based on ZigBee. Journal of Agricultural Engineering, 2013(6): 208-213.

[9] K.M. Du, H.F. Han, Z.F. Sun. Design and application of greenhouse environment remote monitoring system based on ZigBee network. Journal of agricultural engineering, 2014, 25(7):158-163.

[10] X.L. Deng, L.H. Zheng. Farmland information wireless sensor network based on ZigBee and PDA. Journal of agricultural engineering, 2013, 26(2): 103-108.

[11] M.X. Shen, Y.W. Sun, X.F. Zhang, et al. Design of agricultural information service system based on embedded ZigBee technology. Journal of agricultural machinery, 2013, 41(5):148-151.

[12] Z. Sui, H.Q. Liu, W. Hong. The development of environmental detection system based on the ZigBee protocol. Jilin University Journal of information science, 2013, 29(4): 297-203.

[13] D.X. Wang, Y.H. Zhang, Y.Q. Hong. The application of temperature and humidity sensor SHT15 in embedded system. Electronic design engineering, 2014,19(2): 40-43.

[14] N. Lu, Y. Guo. The large shed temperature and humidity control system based on the ZigBee technology. Current generation electronic technology, 2014,15(278): 98-100.

[15] J.H. Liu. Data acquisition and monitoring system based on Kingview. Qingdao Technological University, 2014, 29(4): 106-107. 